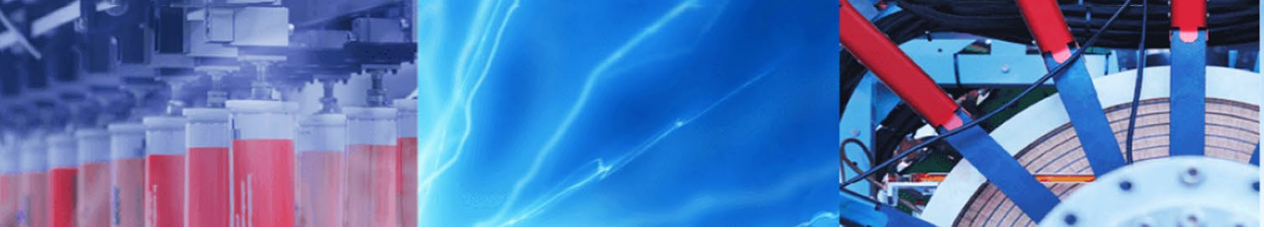

Research Article

\title{
Design and implementation of a power smoothing system for cross-flow current turbines
}

\author{
Hannah Aaronson ${ }^{1,2} \cdot$ Brian Polagye $^{1} \cdot$ Brian Johnson $^{3} \cdot$ Robert J. Cavagnaro ${ }^{4,5}$
}

Received: 18 March 2020 / Accepted: 25 February 2021 / Published online: 12 March 2021

(C) The Author(s) 2021 OPEN

\begin{abstract}
This study presents an efficient system that smooths fluctuations in electrical power from a cross-flow (i.e., "vertical-axis") turbine. The proposed solution is a two-stage approach consisting of a low-pass filter and a bi-directional buck-boost converter. The design and stability characteristics of the system are presented, followed by time-domain simulation and validation against small-scale experiments. When this validated simulation is applied to a full-scale system, we demonstrate a $99 \%$ root mean square reduction in fluctuating power output with only a $3 \%$ drop in electrical system efficiency. This could allow intracycle control strategies to increase mechanical power output without causing electrical power fluctuations that are incompatible with direct use.
\end{abstract}

Keywords Current turbines · Power smoothing $\cdot$ Energy storage $\cdot$ Supercapacitors $\cdot$ Simulation

\section{Introduction}

One of the largest challenges for the electrical integration of distributed renewable resources is power fluctuation over both relatively short and long time scales [1]. Intermittent and unpredictable power from renewable resources, used to offset climate change associated with dispatchable fossil-fuel resources, may disrupt the stability of the power grid and the balance of supply and demand. Long-term power intermittency is a well-established concern in the renewable energy industry, and the feasibility of grid-scale energy storage systems (e.g., pumped hydropower, compressed-air storage) to mitigate this is an active area of research $[2,3]$. Short-term power fluctuation is also problematic. For example, in wind energy generation, incident resource power is proportional to the cube of wind speed, such that turbulent gusts can disrupt grid frequency or cause voltage flicker [4].
Like generation from other renewable resources, current turbines operating in rivers, tidal channels, and strong ocean currents will be required to adhere to distribution and transmission grid standards [5]. Early market adoption is most likely in remote locations where conventional energy costs are higher and current turbines may be costeffective [6]. However, for these remote microgrids, power quality of electrical generation is a particular concern [7].

Cross-flow turbines ("vertical-axis") have distinct, potentially advantageous properties compared to axial-flow turbines ("horizontal-axis"), including lower maximum blade speed, bi-directional functionality in reversing tidal flows, and potential to increase system efficiency in tightlypacked, high-blockage arrays [8, 9]. Typical control strategies involve maintaining an optimal tip-speed ratio for a given inflow velocity through regulation of rotor speed or torque [10]. Turbines with a high mechanical conversion efficiency (i.e., power in flow to power on shaft) typically have a small number of straight blades [11]. Because of

$\triangle$ Hannah Aaronson, haaronson@tesla.com | 'Department of Mechanical Engineering, University of Washington, Seattle, WA, USA. ${ }^{2}$ Present Address: Tesla, Inc., Palo Alto, CA, USA. ${ }^{3}$ Department of Electrical and Computer Engineering, University of Washington, Seattle, WA, USA. ${ }^{4}$ Pacific Northwest National Laboratory, Sequim, WA, USA. ${ }^{5}$ Applied Physics Lab, University of Washington, Seattle, WA, USA. 
the variation in apparent angle of attack for the rotating blades, hydrodynamic torque varies periodically with blade position, leading to oscillations in mechanical power over a single rotation. The primary frequency of oscillation is the product of rotation rate and number of turbine blades. Depending on the control scheme, this instantaneous power can cycle between production (generating) and consumption (motoring) when net power is produced over a rotation [10]. Further, it has been demonstrated that optimizing the amplitude and frequency of turbine speed within a rotation, termed "intracycle control", can increase mechanical conversion efficiency by up to $59 \%$ [12]. However, this increases the peak-to-average ratio of mechanical power, such that the associated electrical power may not be compatible with direct use [13].

Fig. 1 compares the active power delivered to the grid, normalized by average power, for a two-bladed turbine rotating at $\approx 1 \mathrm{~Hz}$ utilizing constant speed or intracycle control [13]. Intracycle control increases the average power, but instantaneous power is characterized by large peak-to-peak power ratio ( $>25$ ) and periodic power consumption. The design and implementation of a power smoothing system (PSS) and control scheme to mitigate these fluctuations, while introducing minimal power loss, is presented in this work. Such a system allows the turbine to be optimized for average power output, thus potentially reducing cost of energy, while delivering stable, highquality power to an end use. The system comprises of two parts: an LC filter and a bi-directional DC-DC converter coupled with a capacitor for short-term (i.e., intracycle) energy storage.

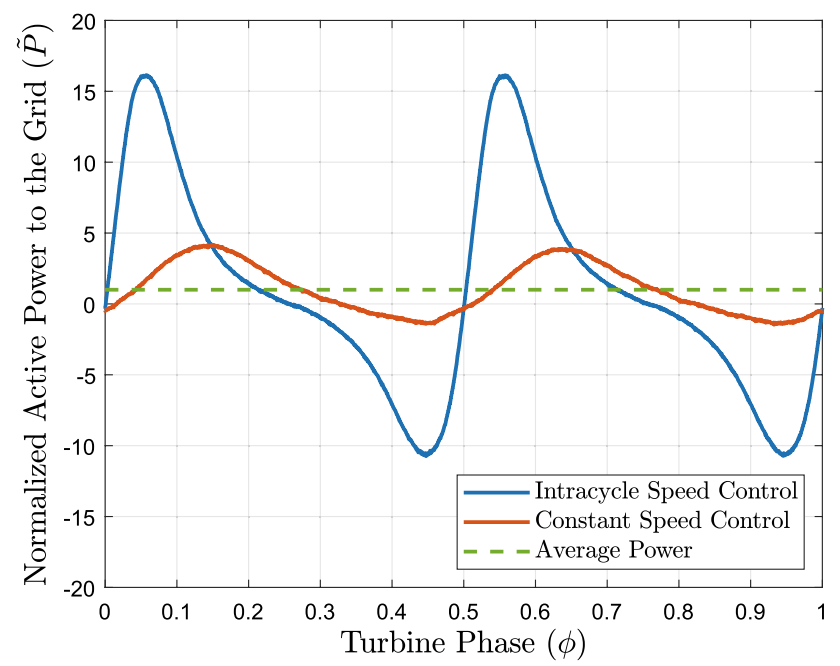

Fig. 1 Active power normalized by average power as a function of rotational phase for a current turbine utilizing differing control schemes. Adapted from [13]
Power smoothing is necessary for other renewable energy generators, including axial-flow wind turbines [14-16] and wave energy converters [17]. In solar photovoltaic (PV) systems, single phase grid-tie inverters are known to introduce power ripple at double the grid frequency onto the DC bus, which can degrade PV system performance. Ripple port circuits, typically a power decoupling circuit integrated on to the DC bus, can absorb these power fluctuations [18-20]. In general, ripple port and other power smoothing systems are designed for the characteristics of specific applications, utilizing topologies such as DC-DC converters, DC-AC H-bridge inverters, flyback converters, or active filters, and deploy energy storage devices such as supercapacitors, batteries, or flywheels.

In this work, we show how a PSS can be designed for the specific electrical power characteristics of cross-flow current turbines operating under intracycle control which results in power fluctuations that are an order of magnitude higher than in other renewable energy systems and requires intermittent power draw. This necessitates an additional LC filter on the DC bus to smooth power over a complete rotation, which is unnecessary for loweramplitude power fluctuations. The main contributions of this work are to 1) demonstrate the effectiveness of PSS on a cross-flow turbine utilizing intracycle control and 2) validate a simulation of the proposed PSS using a benchtop experiment. This work is based on the corresponding author's masters thesis [21], which contains supplementary detail and results.

The remainder of the paper is laid out as follows. Section 2 describes the design and optimization of the PSS and controller, as well as its implementation in a benchtop system and equivalent simulation. Section 3 shows experimental results from the bench-top system which validate the corresponding simulation. The performance and feasibility of a larger-scale system for a cross-flow turbine operating under intracycle control is then demonstrated through simulation.

\section{Methodology}

The power smoothing system, integrated on the DC bus of a generator-to-grid power collection scheme, is shown schematically in Fig. 2. The instantaneous active power shown in Fig. 1 is measured at the three-phase intersection with the grid, shown in green, without the use of the PSS system on the DC bus. The inputs to the system are a time series of the expected turbine rotational rate and control torque, derived from experimental measurements [13].

The proposed PSS is the combination of an LC filter and a bi-directional DC-DC converter utilizing 


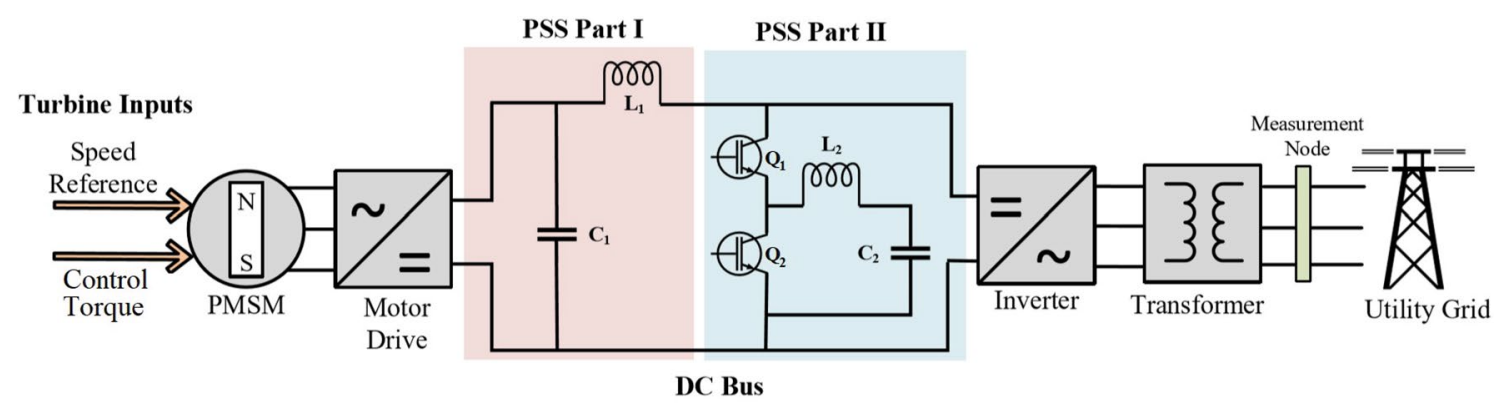

Fig. 2 Generator-to-grid power collector simulation layout including the proposed power smoothing system (PSS)

Proportional-Integral (PI) current control. The LC filter (PSS Part I) is sized to smooth rapidly switching current on the DC bus arising from the motor drive control system which regulates turbine rotation. The $L C$ filter attenuates high-frequency fluctuations $(>20 \mathrm{kHz})$ in $\mathrm{DC}$ bus current and yields low-frequency, low-amplitude current $(<10 \mathrm{~Hz})$. Because these residual power oscillations are undesirable, the DC-DC converter (PSS Part II) uses a high-bandwidth controller to rapid-ly regulate current through the output inductor and capacitor. The charging and discharging of these short-term energy storage components at the bladepass frequency of the turbine is designed to eliminate residual power oscillation.

\subsection{System design}

The cut-off frequency of the low pass filter in PSS Part I is given by,

$f_{c}=\frac{1}{2 \pi \sqrt{L_{1} C_{1}}}$

where $L_{1}$ is inductance and $C_{1}$ is capacitance. This attenuates frequencies above $f_{c}$ at $20 \mathrm{~dB} /$ decade. The capacitor size is a function of the cycle-average energy $E$ produced from the turbine and voltage $V$ across $C_{1}$, given by

$C_{1}=\frac{2 E}{V^{2}}$

To achieve a desired cut-off frequency, maximizing $C_{1}$ and minimizing $L_{1}$ reduces equivalent series resistance (ESR) in the circuit. A large capacitor has the added benefit of stabilizing the voltage input to the motor drive, but this must be balanced against relatively high component cost [22].

Part II of the power smoothing system takes the lowfrequency filtered current from Part I and removes residual fluctuations such that power output to the grid is constant in time. This is achieved by a bi-directional DC-DC converter, where the inductor and capacitor $\left(L_{2}\right.$ and $\left.C_{2}\right)$ serve as short-term energy storage components. The synchronous switches $\left(Q_{1}\right.$ and $\left.Q_{2}\right)$ of the power converter are controlled at the switching frequency by the duty cycle $D$, the active input to this part of the PSS. The duty cycle determines the percentage of time over the switching period the top switch is on and storing energy in $L_{1}$ and $C_{1}$. For the remainder of the switching period $(1-D)$, the bottom switch is on and energy is released from $L_{1}$ and $C_{1}$. A closed-loop PI controller is used to calculate $D$ in real time.

The approach to regulating duty cycle is shown in Fig. 3, which was adapted from a system for smoothing power draw by a machine tool [23]. First, measurements of $I_{L 1}$ and $V_{\text {bus }}$ (Fig. 3, bottom center) are used to calculate the instantaneous power $P_{D C}$ on the $D C$ bus. A digital low pass filter (LPF) estimates the running-average power, $\bar{P}_{D C}$ - the desired constant power output from the DC-DC converter. The difference between average and instantaneous power $P_{\text {ref }}$ must be handled by the PSS. The quotient of $P_{\text {ref }}$ and the capacitor voltage $V_{C 2}$ gives the current to be demanded through the inductor, $I_{\text {ref }}$. Mathematically, this is given as

$I_{\text {ref }}=\frac{P_{\text {ref }}}{V_{C 2}}=\frac{I_{L 1} V_{\text {bus }}-\bar{P}_{D C}}{V_{C 2}}$.

$I_{\text {ref }}$ is compared to the measured inductor current $I_{L 2}$, and the difference between the two is the PI controller's error metric $e$.

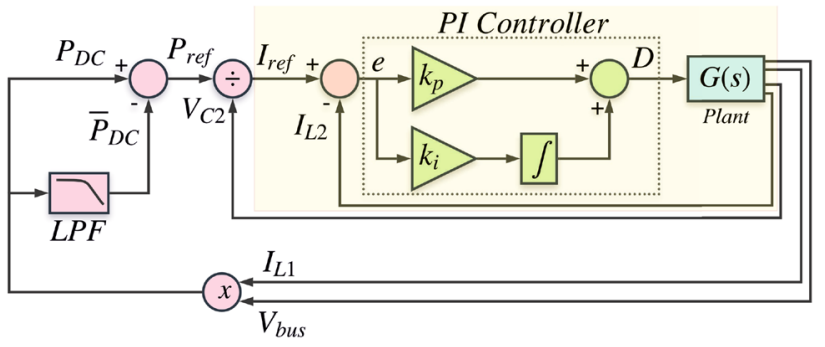

Fig. 3 Layout of the controller used in PSS Part II. Terms are defined in the narrative 
The duty cycle, $D$, is given as

$D=k_{p} e(t)+k_{i} \int e(t) d t$

where $k_{p}$ and $k_{i}$ are the proportional and integral gains, respectively. $D$ is used to synchronously control the two switches in the buck-boost converter, thus controlling the dynamics of the "plant" (i.e., physical system), simplified as a transfer function $G(s)$ in Fig. 3.

\subsection{Controller performance}

Controller gains must be selected to achieve the desired combination of system bandwidth and stability. Controller gains $k_{p}$ and $k_{i}$ are calculated using the complementary sensitivity function, $T(s)$, defined in terms of an open loop transfer function $/(s)[24]$ as

$T(s)=\frac{I(s)}{1+I(s)}=\frac{k_{i}}{L_{2}} \frac{1+\frac{k_{p}}{k_{i}} s}{s^{2}+\frac{1}{L_{2}}\left(R_{L 2}+k_{i}\right) s+\frac{k_{p}}{L_{2}}}$.

$I(s)$ is defined using $G_{i u}(s)$, a transfer function relating current to voltage across $L_{2}$ (including its equivalent series resistance $R_{L 2}$ ), and $G_{c}(s)$, the $\mathrm{PI}$ controller transfer function. This can be expressed as

$I(s)=G_{i u}(s) G_{c}(s)=\left(\frac{1}{s L_{2}+R_{L 2}}\right)\left(k_{p}+\frac{k_{i}}{s}\right)$.

$T(s)$ is equated to a canonical second-order system,

$T(s)=T_{o} \omega_{o}^{2} \frac{1+\omega_{z} s}{s^{2}+2 \xi \omega_{o} s+\omega_{o}^{2}}$,

characterized by controller damping ratio $\xi$ and controller bandwidth $\omega_{o}$. By equating Eqns. (5) and (7), $k_{p}$ and $k_{i}$ are calculated as

$k_{p}=2 \xi \omega_{o} L_{2}-R_{L 2}$

$k_{i}=\omega_{o}^{2} L_{2}$.

For this system, controller bandwidth is chosen as 500 $\mathrm{rad} / \mathrm{s}$ (10x the cycle-averaged blade pass frequency of the turbine) and damping ratio as 0.4 , resulting in a $k_{p}$ of 2.3 $\Omega$ and $k_{i}$ of $2500 \mathrm{H} / \mathrm{s}^{2}$. This damping ratio is a typical value chosen to limit percent overshoot (\%OS) of the closedloop step response to $25 \%$, based on the relationship

$\%$ OS $=\exp \left(\frac{-\xi \pi}{\sqrt{1-\xi^{2}}} * 100\right)$.
To analyze controller stability, performance, and robustness before implementing in hardware, a linearized model of the closed-loop buck-boost converter and controller is created. This model is a useful tool for quickly iterating on controller design and component parameters and for quantifying controller performance by observing its timedomain and frequency-domain response. It requires less computational power (and therefore has a faster run time) than a simulation of the full circuit (Section 2.4), capturing dominant low-frequency dynamics while neglecting highfrequency switching pres-ent in a real system or higherorder simulation.

The linearized model uses a state space representation of the buck-boost converter comprising PSS Part II (highlighted in blue in Fig. 2) based on the two possible converter states (i.e., $Q_{1}$ off and $Q_{2}$ on, and vice versa), which is dependent on the system input, duty cycle $D$. The state space system is defined as

$\dot{x}=A x+B u \quad y=C x$

$A=\left[\begin{array}{cc}-\frac{R_{L 2}}{L_{2}} & -\frac{1}{L_{2}} \\ \frac{1}{C_{2}} & 0\end{array}\right] \quad B=\left[\begin{array}{c}\frac{V_{\text {bus }}}{L_{2}} \\ 0\end{array}\right] \quad C=\left[\begin{array}{ll}1 & 0\end{array}\right]$

with the state variable $x$

$x=\left[\begin{array}{l}i_{L 2} \\ v_{C 2}\end{array}\right]$.

A transfer function, utilized to simplify representation of the plant dynamics, is obtained as

$G(s)=C(s l-A)^{-1}$.

The block diagram of the closed-loop control system, consisting of the buck-boost converter and PI controller, is highlighted in yellow in Fig. 3. A transfer function modeling this closed-loop system is given by the complementary sensitivity function, with the open loop transfer function $I(s)$ defined as the product of the plant $G(s)$ and the controller $G_{c}(s)$ transfer functions. The step response for the linearized model is compared to a full system simulation (Section 2.4) of the same circuit in Fig. 4. Both the linearized model and full system model use component parameters $L_{2}$ (and its ESR), $C_{2}$, and $V_{\text {bus }}$ as listed in Table 1 . The step response of the two models are in close agreement, suggesting that the linearized model is a good representation of the full, non-linear simulation on a switch cycle-averaged basis.

The linearized model can be used to assess system stability, robustness, and bandwidth by observing its frequency domain response [25]. A bode plot of the open loop system transfer function $I(s)$, sensitivity function 


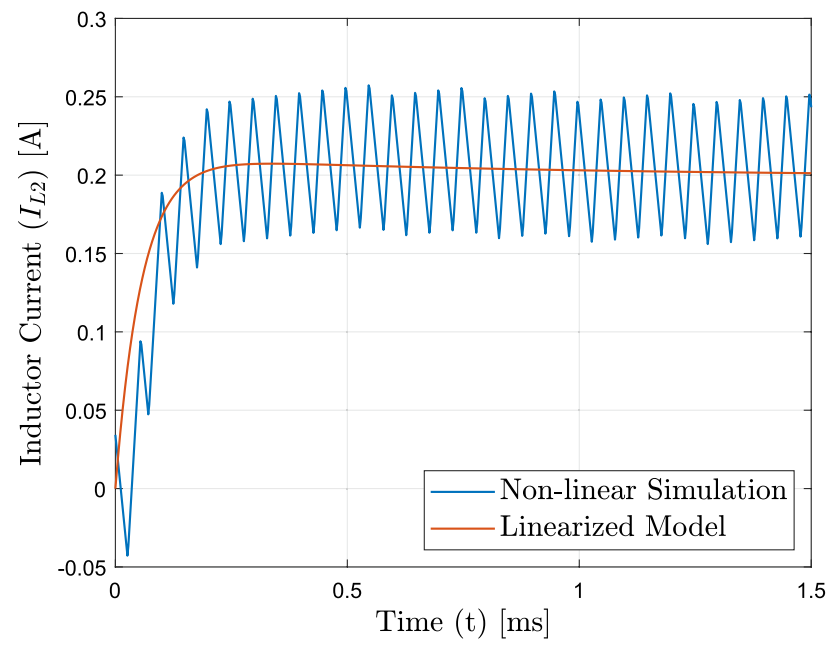

Fig. 4 Comparison of the step response for a linearized model and non-linear simulation

$S(s)$, and the complementary sensitivity function $T(s)$ is given in Fig. $5 . S(s)$ is defined as

$S(s)=\frac{1}{1+I(s)}$.
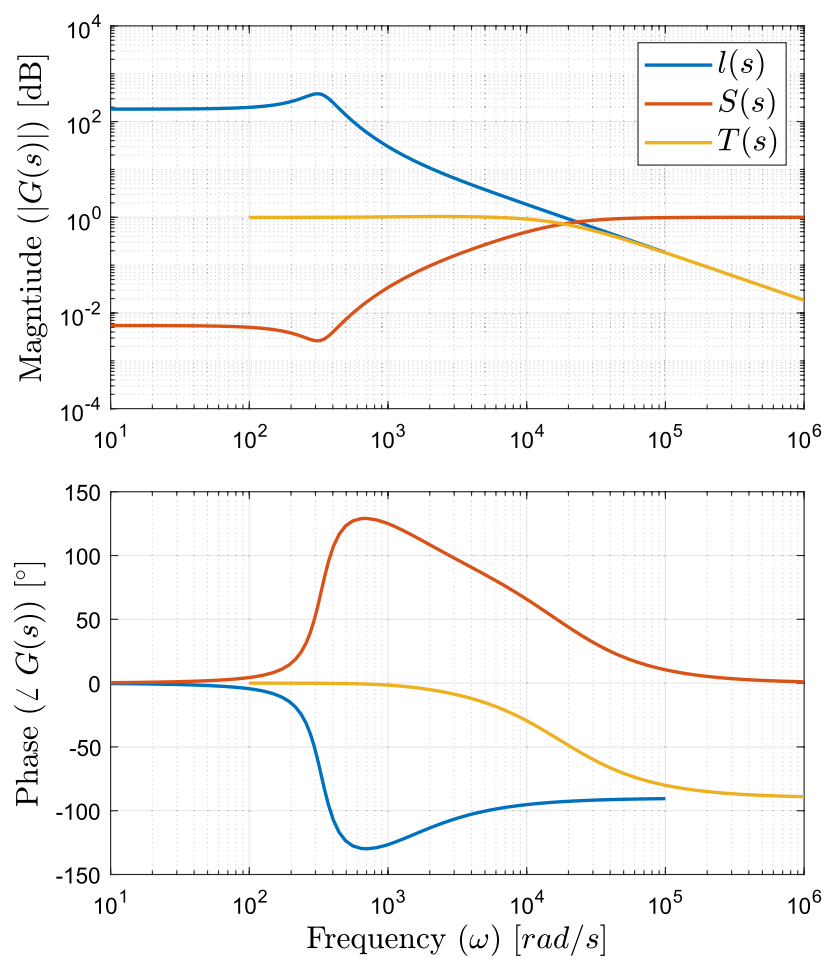

Fig. 5 Bode plot of the open loop transfer function, sensitivity function, and complementary sensitivity function
$S(s)$ shows a small magnitude response at low frequencies $\left(\omega<10^{2} \mathrm{rad} / \mathrm{s}\right)$, meaning the controller will drive error close to zero in this region, forcing the output inductor current to closely track the desired reference. Meanwhile, $T(s)$ shows a magnitude response drop-off at high frequencies $\left(\omega>10^{4} \mathrm{rad} / \mathrm{s}\right)$, resulting in desirable measurement noise attenuation in this region. The gain crossover frequency, or the point where $T(s)$ and $S(s)$ cross, is equivalent to the bandwidth of the controller. This bandwidth is $20 \times 10^{3} \mathrm{rad} / \mathrm{s}$, indicating that the system should have no difficulty smoothing power from a turbine operating with a blade-pass frequency on the order of $10 \mathrm{rad} / \mathrm{s}$.

Robustness relates to how much model uncertainty the system can sustain before going unstable. The true system will have parameters that are slightly different than the model; for example, inductor and capacitor values typically have $\pm 20 \%$ tolerance. If the system is not robust, these differences could push the real system to instability even though it is theoretically stable. Robustness can be evaluated on the basis of the maximum value of the frequency response of the sensitivity function. A relatively large peak at approximately the gain crossover frequency is an indicator of a non-robust system. As shown in Fig. 5, there is no peak and the maximum value of the sensitivity function is $\approx 1$ which indicates that the closed-loop system should tolerate significant changes in parameters without instability. Additionally, the phase margin of the open loop system $/(s)$ is $87^{\circ}$, suggesting that there is a high tolerance to time delay in the real system before instability.

This analysis suggests that the controller and DC-DC converter components can achieve the desired combination of stability, robustness, and performance when implemented in hardware.

\subsection{Bench-top set-up}

The topology used to validate a small-scale version of the PSS (e.g., $10 \mathrm{~W}$ average power output) is shown in Fig. 6 . The system is an abstraction of the DC bus in

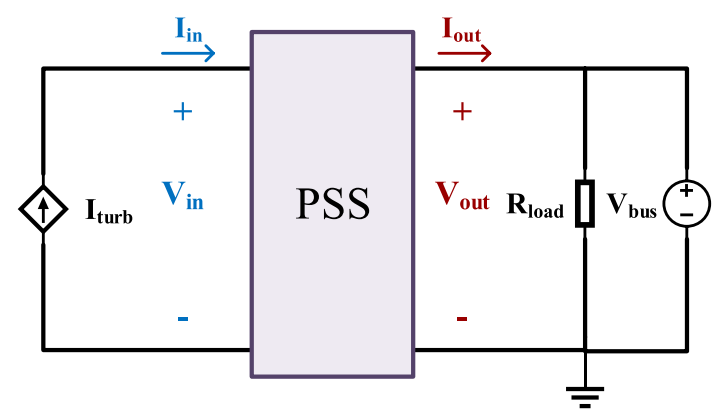

Fig. 6 Bench-test set-up using a simplified abstraction of the DC bus 
Fig. 2, where the turbine, generator, and motor drive are replaced with an equivalent controllable current source input mimicking turbine electrical power output. The inverter, transformer, and utility grid are emulated by a DC voltage source and a resistive load in parallel. This system is not meant to perfectly emulate a gridconnected turbine; rather it is intended to demonstrate the capability of the PSS.

Time series data for the current source input, $l_{\text {turb }}$, is synthesized from experiment and simulation. First, phase-averaged experimental measurements of rotation rate $\omega$ and control torque $\tau$ (equivalent to the electrical torque imposed by a generator [10]) were taken from a laboratory-scale two-bladed turbine operating in a recirculating flume with a mean current velocity of $1 \mathrm{~m} / \mathrm{s}$ and a turbulence intensity of $1.6 \%$. The turbine has radius of $0.086 \mathrm{~m}$, which is 1:5 scale of the full-scale system described in Section 2.4. A servomotor was used to hold rotational speed constant at a tip-speed ratio of 2.2, which maximized time-average mechanical power. This gives a rotor rotational frequency of $4 \mathrm{~Hz}$ and primary oscillation in shaft power at $8 \mathrm{~Hz}$. As the turbulence in the inflow had a dominant frequency $<0.1 \mathrm{~Hz}$, intracycle fluctuations are the dominant periodicity and the phase-average $\tau$ and $\omega$ are good approximations of the time-varying values. The experimental setup is described in more detail in [10].

Second, the phase-average experimental $\omega$ and $\tau$ are used as inputs to the PMSM generator in a simulation of a baseline system (i.e., layout shown in Fig. 2, but without the PSS). Specifically, $\tau$ is prescribed and $\omega$ is taken as the reference speed (i.e., commanded speed). In post-processing, the reference speed is compared to the generator speed to verify that the PSS is not affecting turbine hydrodynamic performance. The characteristics of the simulated generator are modeled after a motor sized for laboratory-scale experiments (Parker SM233ALKPSM). The simulation, implemented in Matlab Simulink, is discussed in further detail in Section 2.4. For the generator, mechanical power input and simulated electrical power output are given by

$P_{\text {mech }}=\tau \omega$

$P_{\text {elec }}=I_{\text {turb }} V_{\text {bus }}$

where $I_{\text {turb }}$ is the current produced by the turbine (and observed on the DC bus) and $V_{\text {bus }}$ is the constant DC bus voltage. Under constant speed control, $\omega$ remains steady while phase-varying torque produces a time varying DC bus current to be smoothed by the PSS. Fig. 7 shows the mechanical power input to the simulation $P_{\text {mech }}$ and the resulting electrical power $P_{\text {elec }}$ observed on the DC bus for

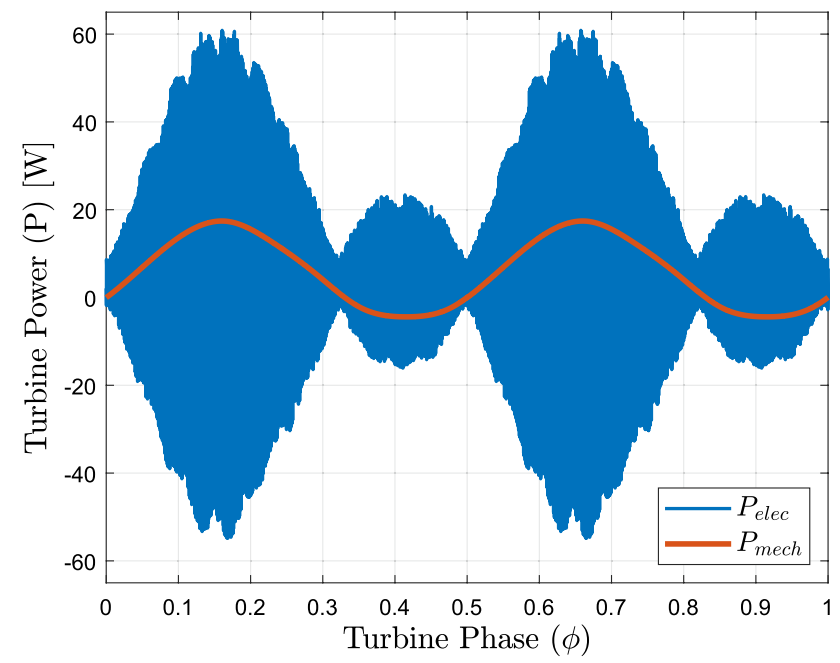

Fig. 7 Mechanical power of the turbine, characterized by sinusoidally fluctuating torque, and the resulting electrical power on the DC bus
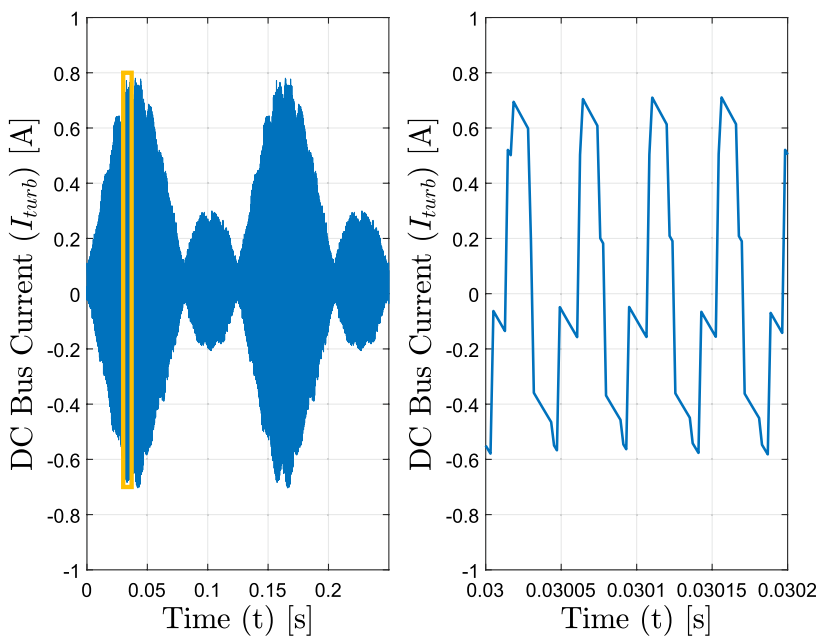

Fig. 8 Electrical current on the DC bus, $I_{\text {turb }}$, over one turbine rotation (left) and $0.25^{\circ}(0.2 \mathrm{~ms})$ of turbine rotation (right)

one turbine rotation. As the turbine is two-bladed, oscillations in mechanical and electrical power occur twice per rotation.

Detail of the DC bus current, $I_{\text {turb }}$, is shown in Fig. 8 . The polarity of current fluctuates rapidly at the rate of the emulated motor drive switching frequency $(20 \mathrm{kHz})$ enacting constant speed control, resulting in a discontinuous waveform with a higher peak-to-average ratio than the turbine mechanical power.

For the benchtop PSS validation, this rapidly fluctuating current is emulated with an arbitrary function generator (Agilent 33220A). An effective current source is realized from the voltage signal output of the function generator $V_{\text {arb }}$ using Thẽvenin and Norton circuit 
equivalents [26]. The voltage source $V_{N}$ required to produce the desired current input $I_{\text {turb }}$ is provided by a high-power operational amplifier, with $V_{a r b}$ on the inverting input and a constant voltage source $V_{\text {ref }}$ on the noninverting input. The current input to the system, $I_{t u r b}$, is given by

$I_{\text {turb }}=\frac{1}{R_{T}}\left(V_{N}-V_{\text {bus }}\right)$

$V_{N}=-\frac{R_{f}}{R_{g}} V_{\text {arb }}+\left(\frac{R_{f}}{R_{g}}+1\right)\left(\frac{R_{1}}{R_{1}+R_{2}}\right) V_{r e f}$

with the resistances, $R$, described in Fig. 9.

The bench-top PSS is shown schematically in Fig. 10 and in implementation in Fig. 11. A summary of all system components and controller parameters is provided in Table 1. Inductor ESRs are measured using a digital multimeter and capacitor values are taken from component data sheets. The DC bus voltage is set at $80 \mathrm{~V}$, consistent with the motor drive selection for this scale

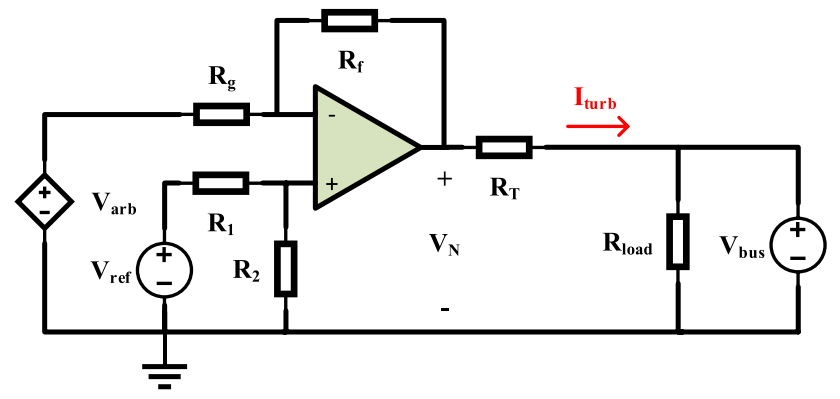

Fig. 9 Operational amplifier used for the bench-top system set-up

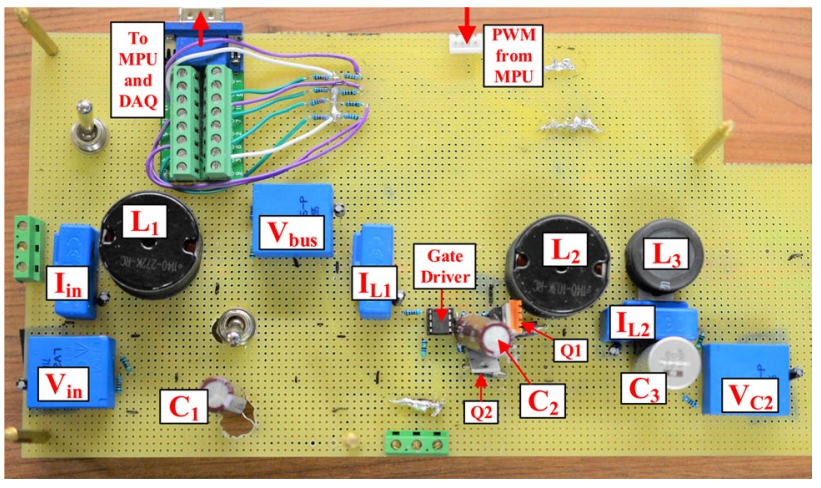

Fig. 11 Hardware implementation of the PSS on a protoboard

of turbine. The cut-off frequency of the PSS Part I LC filter $(150 \mathrm{~Hz})$ is 130 -times lower than the switching frequency of the input current.

The PSS Part II controller is implemented on a TI TMS320F280049C microcontroller (MPU) and TI C2000 LaunchXL breakout board that has a system clock of $10 \mathrm{~ns}$. A symmetrical triangle carrier at $10 \mathrm{kHz}$ is used for PWM generation, with current $\left(I_{L 1}, I_{L 2}\right)$ and voltage $\left(V_{C 2}, V_{\text {bus }}\right)$ sampled at the analog-to-digial converter (ADC) pins twice per switch cycle, when the carrier signal is high or low and these measurements are closest to their cycle-averaged value. Measurements of current (LEM LAH 25-NP) and voltage (LEM LV 25-P) on the input and output of the system are acquired by a data acquisition device (NI DAQ 6353) at a sample rate of $250 \mathrm{kHz}$. Prior to real-time control, the measurements of $V_{\text {bus }}$ $I_{L 1}$, and $V_{C 2}$ are digitally low-pass filtered to mitigate effects of sensor noise. Similarly, an LC filter $\left(L_{3}\right.$ and $\left.C_{3}\right)$ is added to the output of the bench-top system to filter high-frequency switching noise introduced by the DC-DC converter. This

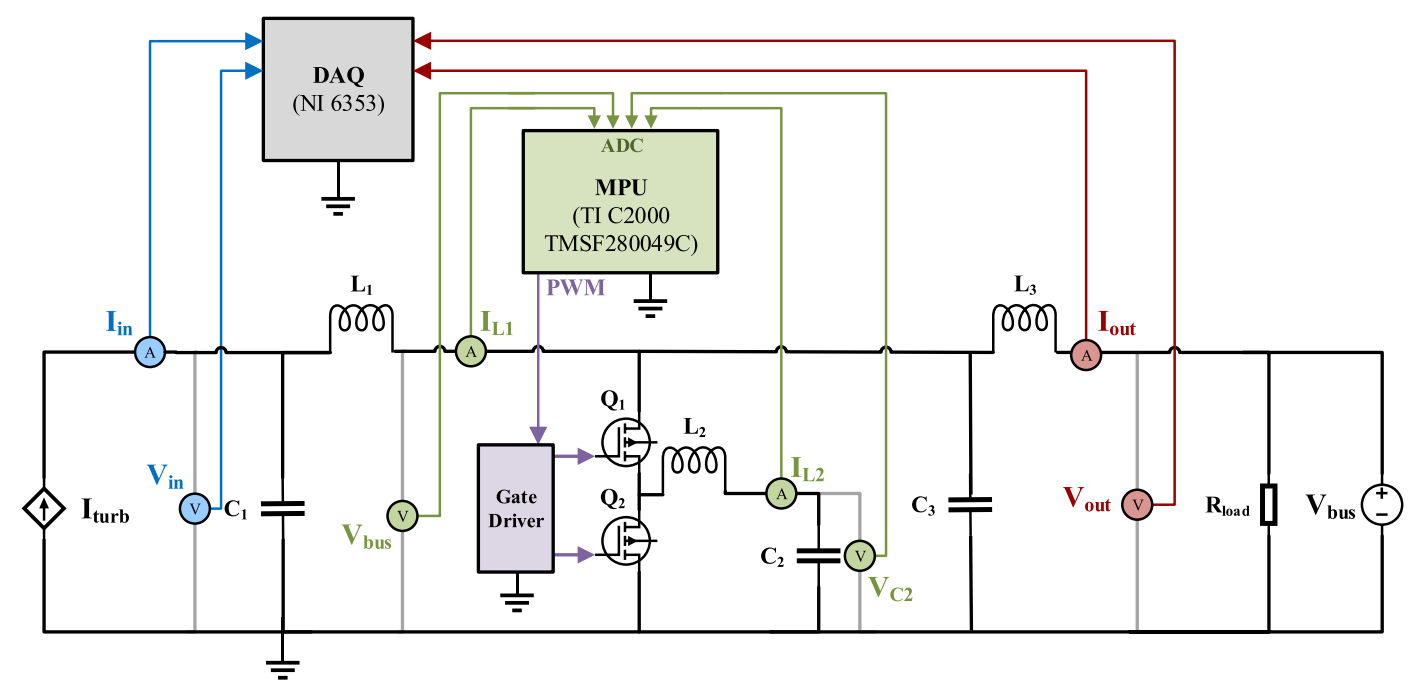

Fig. 10 Schematic of full PSS bench-top set-up. Component naming conventions are identical to Fig. 3 
Table 1 Relevant parameters for the bench-top PSS

\begin{tabular}{|c|c|c|c|c|}
\hline \multicolumn{2}{|c|}{ Set-up components } & \multicolumn{3}{|c|}{ PSS components } \\
\hline Variable & Value & Variable & Value & $\mathrm{ESR}[\mathrm{m} \Omega]$ \\
\hline$R_{f}$ & $30 \mathrm{k} \Omega$ & $L_{1}$ & $2.7 \mathrm{mH}$ & 700 \\
\hline$R_{g}$ & $2 \mathrm{k} \Omega$ & $L_{2}$ & $10 \mathrm{mH}$ & 1700 \\
\hline$R_{1}$ & $10 \mathrm{k} \Omega$ & $L_{3}$ & $1.8 \mathrm{mH}$ & 700 \\
\hline$R_{2}$ & $10 \mathrm{k} \Omega$ & $C_{1}$ & $390 \mu \mathrm{F}$ & 44 \\
\hline$V_{\text {ref }}$ & $10 \mathrm{~V}$ & $C_{2}$ & $910 \mu \mathrm{F}$ & 26 \\
\hline$R_{L}$ & $10 \Omega$ & $C_{3}$ & $390 \mu \mathrm{F}$ & 44 \\
\hline$R_{\text {load }}$ & $50 \Omega$ & \multicolumn{3}{|c|}{ Controller parameters } \\
\hline \multirow[t]{3}{*}{$V_{\text {bus }}$} & \multirow[t]{3}{*}{$80 \mathrm{~V}$} & $f_{s w}$ & $10 \mathrm{kHz}$ & \\
\hline & & $k_{p}$ & $2.3 \Omega$ & \\
\hline & & $k_{i}$ & $2500 \mathrm{H} / \mathrm{s}^{2}$ & \\
\hline
\end{tabular}

allows for easier observation of the low-frequency smoothing capabilities of the system and does not affect the performance metrics used for evaluation. This LC filter would not be needed for a grid-integrated system, since power would be fed through an inverter and converter switching noise on the $D C$ bus would not be observed on the grid side.

Each benchtop experiment consists of 50 emulated turbine rotations (12.5 s) after the system reaches steady state. This test is repeated 10 times and efficiency is calculated for each trial as

$\eta=\frac{\bar{P}_{\text {out }}}{\bar{P}_{\text {in }}}$,

where $P_{\text {in }}$ is the product of input current and voltage $\left(I_{\text {in }}\right.$ and $\left.V_{\text {in }}\right), P_{\text {out }}$ is the product of output current and voltage $\left(I_{\text {out }}\right.$ and $\left.V_{\text {out }}\right)$, and the overbar denotes an average over an integer number of rotations. PSS efficiency is reported as an average over all trials.

System performance is evaluated in the frequency domain by a periodogram of input and output DC bus electrical power $\left(P_{\text {in }}\right.$ and $\left.P_{\text {out }}\right)$ [27]. Periodograms are computed for all ten trials and the amplitude of the periodogram, $P_{P G}$ (in $W^{2}$ ) from each frequency bin is averaged across all trials to yield an average, $\bar{P}_{P G}$. The root mean square (RMS) of the oscillating component of $P_{\text {in }}$ and $P_{\text {out }}$ across a specified range of frequencies can be calculated from this averaged power spectra as

$P_{r m s}=\sqrt{\frac{\sum_{i=2}^{N}\left(\bar{P}_{P G, i}\right)}{L-1}}$

where $\bar{P}_{P G, i}$ is the magnitude of the power spectra at each frequency, $N$ is the number of frequencies of interest, and $L$ is the number of samples in the time series. $P_{\text {rms, low }}$ is used to denote $P_{r m s}$ at low frequencies (i.e., up to $100 \mathrm{~Hz}$ ). By neglecting contributions of high-frequency converter switching and sensor noise, $P_{\text {rms, low }}$ captures the ability of the PSS to remove dominant low-frequency power oscillations caused by time-varying turbine mechanical power. Applying Eqn. (21) across all frequencies is equivalent to calculating the RMS of oscillating power in the time domain, given by

$P_{r m s, t o t}=\sqrt{\frac{\sum_{i=1}^{L}\left(P_{i}-\bar{P}\right)^{2}}{L-1}}$

where oscillating power is defined as a time series of instantaneous power minus average power $(P-\bar{P})$.

\subsection{Simulation set-up}

As previously mentioned, PSS simulation is carried out in Matlab Simulink. The simulation of the benchtop PSS matches the topology shown in Fig. 10, including a controllable current source input configured to match the input current $l_{\text {in }}$ measured in benchtop PSS experiments. As in the experimental system, this replaces all turbine and generator dynamics with a single input representing the expected current on the DC bus. All component and controller parameters listed in Table 1 are used in the simulation, which uses a fixed-step discrete solver with step size $1 \mathrm{E}-6$ (which yields time-step invariant results). The controller is configured inside of a triggered subsystem to execute when the PWM carrier signal is at its maximum and minimum to match the MPU hardware configuration. Between triggers, there is a zero-order hold on the measured values, capturing the effect of real-time controller delay. After reaching steady state, the model is run for 50 emulated turbine rotations, and the input and output power is measured to calculate efficiency and frequencydomain improvements in power quality.

To demonstrate the viability of the PSS design for a larger-scale system utilizing intracycle control, a generator-to-grid simulation is used, matching that shown in Fig. 2. The rotor speed and control torque inputs to the simulation are based on the phase-average coefficients of control torque and tip-speed ratio for an intracycle control strategy [13]. For a full-scale turbine with a projected frontal area of $1 \mathrm{~m}^{2}$ operating in a steady inflow velocity of $2 \mathrm{~m} / \mathrm{s}$, this yields $1 \mathrm{~kW}$ average electrical power [13]. The full-scale PSS is implemented in simulation in the same manner as for the benchtop system simulation, using the same solver, step size, and triggered subsystem for the controller. Larger inductors and capacitors are required, matching available off-the-shelf components, to handle the higher average power and DC bus voltage $(480 \mathrm{~V})$. A summary of controller parameters, components, and their estimated costs are listed in Table 2. 
Table 2 List of controller parameters and components for the full-scale system

\begin{tabular}{|c|c|c|c|c|}
\hline \multicolumn{5}{|c|}{ Controller parameters } \\
\hline$k_{i}$ & $478 \Omega$ & $f_{s w}$ & $10 \mathrm{kHz}$ & \\
\hline$k_{p}$ & $3.10 \mathrm{H} / \mathrm{s}^{2}$ & & & \\
\hline \multicolumn{5}{|c|}{ System components } \\
\hline Component & Size & Rating & $\mathrm{ESR}[\mathrm{m} \Omega]$ & Cost \\
\hline$C_{1}$ & $1.93 \mathrm{~F}$ & $480 \mathrm{~V}$ & 720 & $\$ 3,969$ \\
\hline$L_{1}$ & $32 \mathrm{mH}$ & $10 \mathrm{~A}$ & 28 & $\$ 43$ \\
\hline$C_{2}$ & $0.05 \mathrm{~F}$ & $320 V$ & 12 & $\$ 557$ \\
\hline \multirow[t]{2}{*}{$L_{2}$} & $32 \mathrm{mH}$ & $10 \mathrm{~A}$ & 28 & $\$ 43$ \\
\hline & & & Total Cost & $\$ 4611$ \\
\hline
\end{tabular}

\section{Results and discussion}

\subsection{Benchtop PSS}

A comparison between the experimental and simulated system performance is shown in Fig. 12. The fluctuating input power, shown in blue, is initially smoothed using only the LC filter in Part I of the PSS. Here, the DC-DC converter is on, with a constant duty cycle of 0.5 , holding $C_{2}$ at a steady $40 \mathrm{~V}$. This allows for a smooth transition with no large current transients when the controller switches on. The Part II controller switches on midway through, varying duty cycle with turbine position to remove the remaining sinusoidal fluctuations in output power.

Fig. 12 shows good agreement between the simulated and experimental results. The main difference is high-frequency switching noise from the DC-DC converter in the experiment that is absent in simulation. This is an artifact of the prototype setup caused by switch-node ringing in the converter and could be mitigated by implementing the system on a printed circuit board, where the gate driver circuity, switches, and output capacitor could be physically located closer together to minimize parasitic inductance.

Table 3 compares experimental and simulated system efficiency and reduction in low-frequency $(<100$ $\mathrm{Hz}$ ) power oscillations. For PSS Part I results, PSS Part II is completely disconnected to isolate the effect of the $\mathrm{LC}$ filter. Simulation shows a $98.5 \%$ reduction in undesirable low frequency oscillating power $\left(P_{r m s, l o w}\right)$ while maintaining greater than $99 \%$ efficiency. Experimental results show a slightly reduced performance, with a $94.7 \%$ reduction in $P_{r m s, l o w}$ at $89.5 \%$ efficiency. The efficiency decrease is primarily attributable to DC-DC converter losses from non-zero switching times. Efficiency across the ten experimental trials is consistent, with a standard deviation of $0.023 \%$. Table 3 shows that PSS Part I does
Table 3 Comparison in experimental and simulated PSS performance for the benchtop system

\begin{tabular}{lcc}
\hline System & Simulation & Experiment \\
\hline Efficiency $(\eta)[\%]$ & & \\
No PSS & $100 \%$ & $100 \%$ \\
PSS Part I & $100 \%$ & $99.7 \%$ \\
PSS Part II & $99.8 \%$ & $89.5 \%$ \\
Low-frequency power $\left(P_{\text {rms,low }}\right)[\mathrm{W}]$ & \\
No PSS & 2.37 & 2.37 \\
PSS Part I & 2.37 & 2.17 \\
PSS Part II & 0.034 & 0.130 \\
\hline
\end{tabular}

not significantly affect low-frequency oscillations, as expected given the LC filter cut-off frequency of $130 \mathrm{~Hz}$.

A comparison between the reference current, $I_{\text {ref }}$, and measured current, $I_{L 2}$, for the simulation and experiment, is shown in Fig. 13. In simulation, there is almost perfect tracking between the measured and reference current, with an RMS error of $7.1 \mathrm{~mA}$, which is small compared to the current range of $230 \mathrm{~mA}$. In experiment, switch node ringing and noise leads to a larger RMS error of $32.5 \mathrm{~mA}$ and contributes to the poorer performance. A higher switching frequency would increase controller response bandwidth and simplify filtering of switching noise, but would also increase switching losses and, therefore, reduce system efficiency.

\subsection{Large-scale system}

Results of the large-scale PSS simulation for a turbine utilizing intracycle control are shown in Fig. 14. For a baseline simulation without PSS, low-frequency power $P_{r m s, \text { low }}$ is initially $7.1 \mathrm{~kW}$ per cycle, 7-times larger than the average power generated by the turbine. With the PSS, low-frequency power is reduced by $99.8 \%$ with $97.0 \%$ efficiency. This means that the inverter, transformer, and transmission 

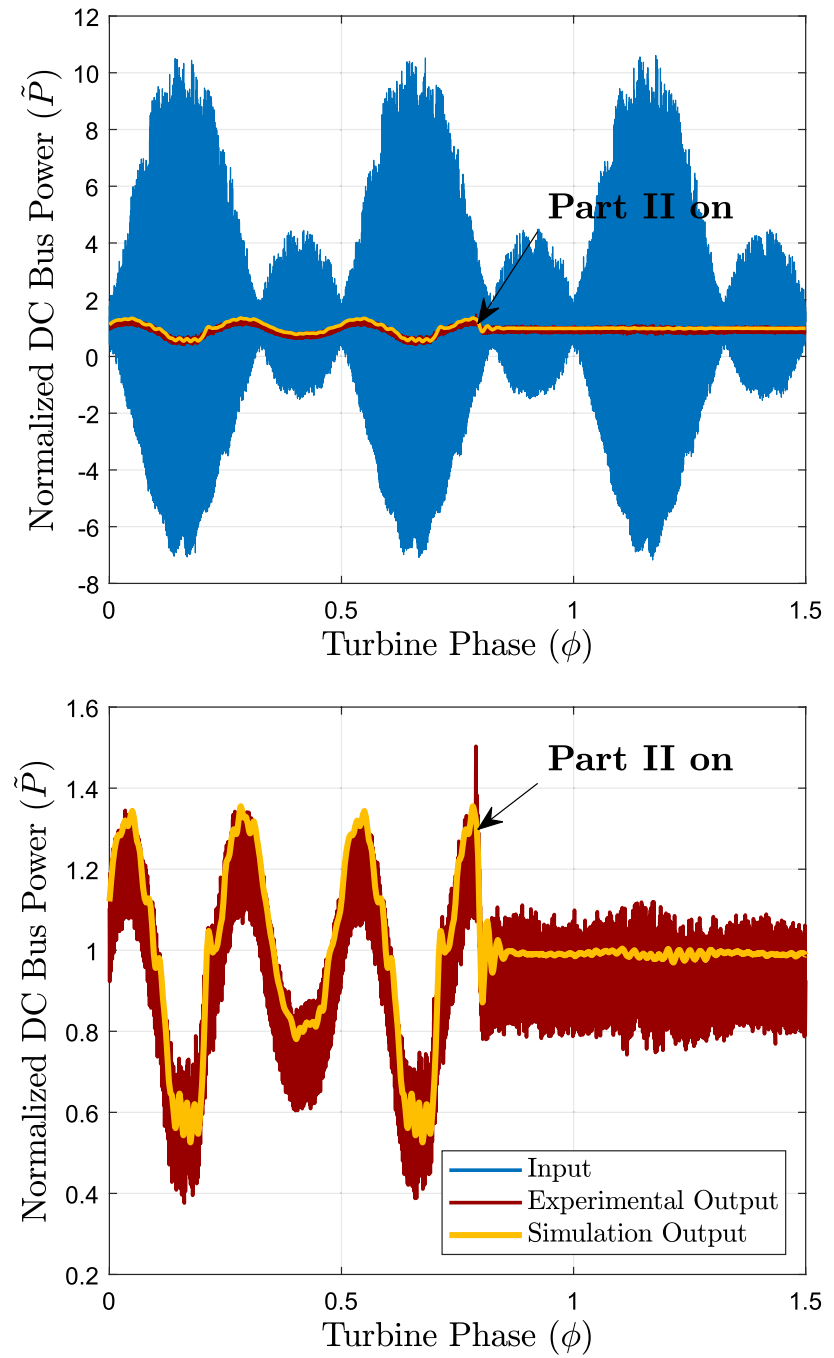

Fig. 12 Demonstration of the PSS smoothing input power (top) and a comparison of experimental and simulated DC bus power (bottom)

line used to connect the DC bus to the utility grid could be rated to significantly lower currents than for a system without the PSS.

The implementation of the PSS on the DC bus does not affect turbine hydrodynamics or its mechanical efficiency. As long as the PSS components are sized appropriately, the DC bus voltage input to the generator will remain steady and the generator will produce or consume electrical current as needed to maintain the commanded turbine speed. In other words, a well-designed PSS should not affect the hydrodynamic performance of turbine. For example, in the full-scale simulation, no deviation between command speed and generator speed is observed with the specified components. However, if components are not sized correctly, generator speed diverges from command speed.
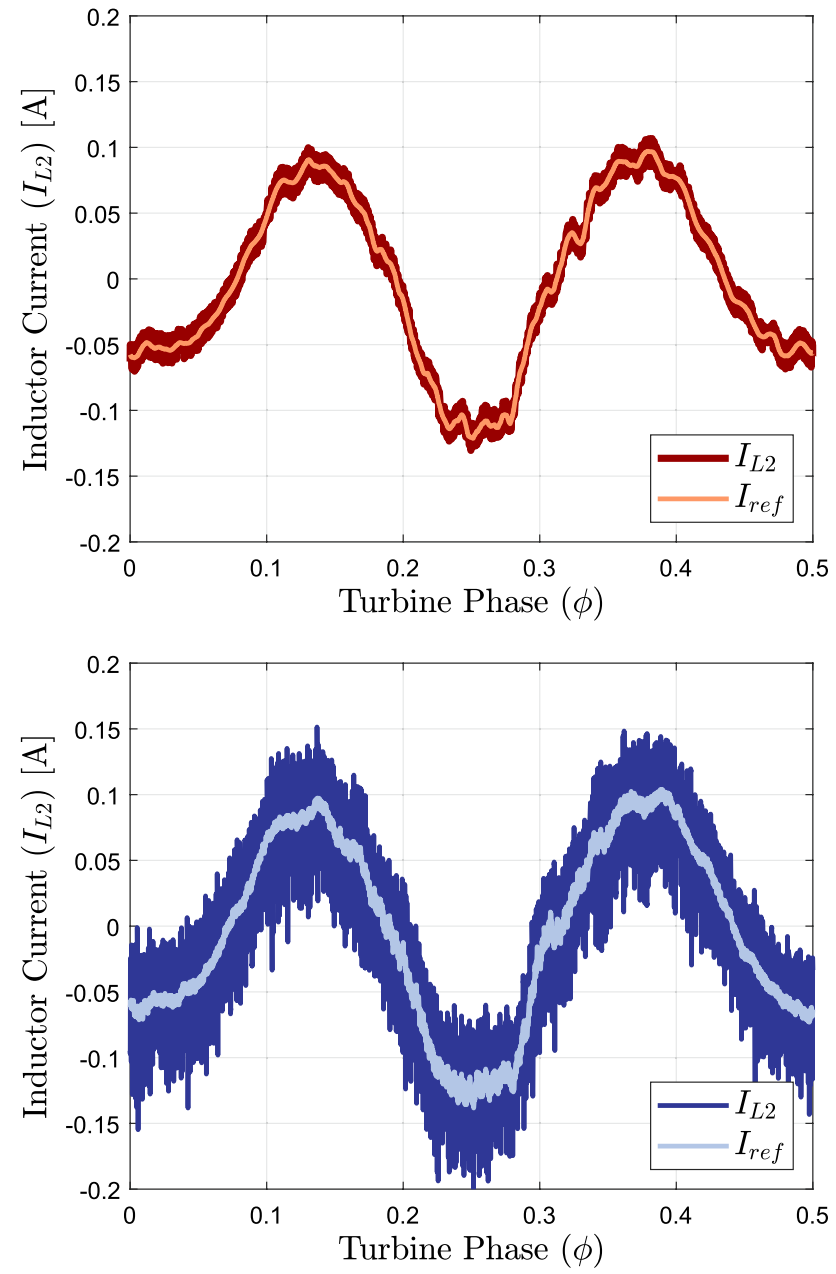

Fig. 13 Comparison between the commanded and measured current for the simulated (top) and experimental (bottom) system

\subsection{Extensions to other systems}

In laboratory experiments to characterize turbine performance, intracycle fluctuations in $\tau$ dominate over turbulence. This will not necessarily be the case for a larger turbine operating in a natural environment. Consequently, turbulence may cause larger fluctuations in output power than considered here. However, the overall design of a capacitor-based PSS is well suited to smooth variation in electrical power resulting from turbulence [22], which will be substantially smaller than the intracycle variation (i.e., order of magnitude oscillation within a single rotation).

All our simulations and experiments focus on a twobladed cross-flow turbine with straight blades. This represents a relatively extreme case for variations in power output. Torque oscillation frequency is proportional to the number of blades and, as the blade count increases, the amplitude of the torque oscillation is also reduced. For turbines with a higher blade count, PSS components 


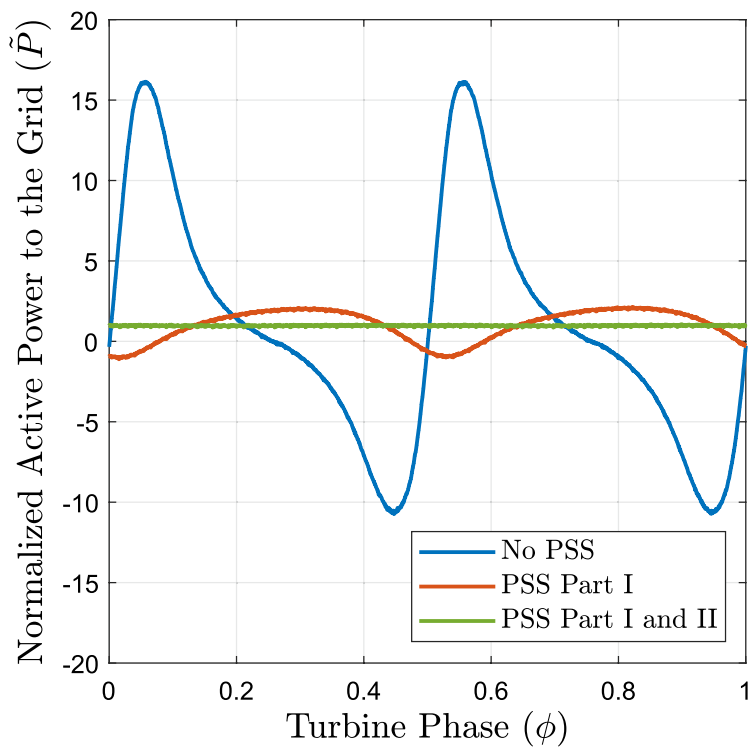

Fig. 14 Comparison in active power delivered to the grid for a full scale turbine utilizing the large-scale PSS

could be downsized, as the components from Part II would absorb less energy with each turbine rotation.

Further simplification to the PSS may be possible. For example, an alternative system design could forego the $L C$ filter in Part I and estimate DC bus power, $P_{D C}$, using measurements on the generator side. In this arrangement, $P_{D C}$ can be estimated using the dot product of back-EMF voltage, $V_{e m f}$, and three phase AC current, $I_{a b c}$, measured on the generator stator windings, given by

$P_{D C} \approx V_{e m f} \cdot I_{a b c}=p \lambda \dot{\Theta}\left[\begin{array}{c}\cos (p \Theta) \\ \cos \left(p\left(\Theta-\frac{2 \pi}{3}\right)\right) \\ \cos \left(p\left(\Theta+\frac{2 \pi}{3}\right)\right)\end{array}\right] \cdot\left[\begin{array}{c}I_{a} \\ I_{b} \\ I_{c}\end{array}\right]$

where $p$ is the number of generator pole pairs, $\lambda$ is flux linkage, $\Theta$ is rotor position, and $\dot{\Theta}$ is rotor speed. The power delivered to the grid when simulating the large-scale PSS with this method, which still includes a large input capacitor $C_{1}$ but does not include $L_{1}$, is shown in Fig. 15 .

While this approach performs relatively well, the control errors at phases of turbine rotation when instantaneous power changed most rapidly (at $0^{\circ}$ and $180^{\circ}$ ) contribute to intermittent power draw from the grid. However, this suggests that, as peak-to-average power ratio decreases, an approach that forgoes PSS Part I could be effective. This approach also utilizes existing generator side current and voltage measurements, whereas the full system is entirely self contained on the DC bus.

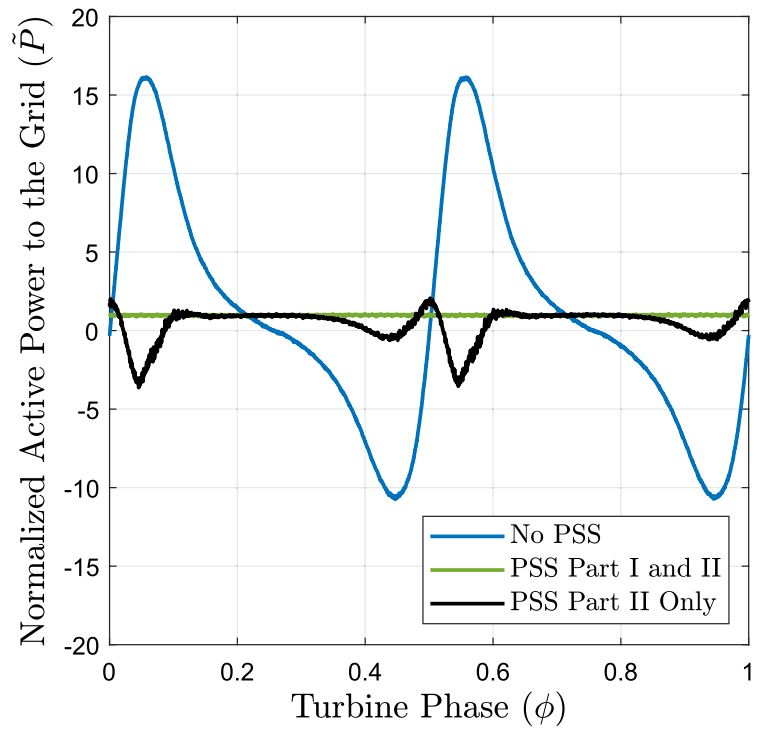

Fig. 15 Active power delivered to the grid for the large-scale PSS system without the Part I LC filter

\section{Conclusion}

Cross-flow turbine design and control schemes used to maximize average power output may produce instantaneous power that, in its raw form, is unsuitable for end-use, particularly in remote communities with weak grids or directly-coupled electric loads. A simple power smoothing system is proposed to transform power on the $D C$ bus with order of magnitude oscillations on time scales of $<1$ $s$ to steady, consistent power delivered to an end-use. This power smoothing system allows the turbine and mechanical control scheme to maximize average generated power; power quality can be subsequently improved with a limited efficiency penalty.

The proposed two-part system has been shown, in simulation, to reduce low-frequency power oscillations by $98 \%$ with negligible efficiency penalty. These results have been validated using a bench-top system, with slightly reduced performance and efficiency arising from switchnode ringing from parasitic inductance, losses from nonzero switching times, and sensor noise - all of which could be mitigated in a commercial design. A larger-scale version is demonstrated in simulation for a turbine utilizing intracycle control, where low-frequency power oscillations are reduced by $99 \%$ with $3 \%$ power loss.

A limitation to this work is that the experimental validation is for the power input from a small-scale turbine utilizing constant speed control. Future work could include validating the larger-scale version of the system and deploying it in the field on a turbine operating with a more complex intracycle control scheme. Such a system could employ improved circuit design practices to 
mitigate the implementation issues identified at smallscale and achieve efficiencies closer to those predicted by simulation.

Author Contributions All authors contribute to: Conceptualization, Methodology, Investigation, Writing-review \& Editing. B. Polagye also was responsible to: Funding acquisition and Supervision.

Funding This work is supported by the U.S. Department of Defense Naval Facilities Engineering Command.

Data availability The supporting data are available from the corresponding author upon reasonable request.

\section{Declarations}

Conflict of interest On behalf of all authors, the corresponding author states that there is no conflict of interest.

Open Access This article is licensed under a Creative Commons Attribution 4.0 International License, which permits use, sharing, adaptation, distribution and reproduction in any medium or format, as long as you give appropriate credit to the original author(s) and the source, provide a link to the Creative Commons licence, and indicate if changes were made. The images or other third party material in this article are included in the article's Creative Commons licence, unless indicated otherwise in a credit line to the material. If material is not included in the article's Creative Commons licence and your intended use is not permitted by statutory regulation or exceeds the permitted use, you will need to obtain permission directly from the copyright holder. To view a copy of this licence, visit http://creativecommons .org/licenses/by/4.0/.

\section{References}

1. Evans A, Strezov V, Evans TJ (2012) Assessment of utility energy storage options for increased renewable energy penetration. Renew Sustain Energy Rev 16(6):4141-4147. https:// doi.org/10.1016/j.rser.2012.03.048

2. Rastler D (2010) Electricity energy storage technology options: A white paper primer on applications, costs, and benefits. Technical report, Electric Power Research Institute. http:// large.stanford.edu/courses/2012/ph240/doshay1/docs/EPRI. pdf

3. Denholm P, Ela E, Kirby B, Milligan M (2010) Role of energy storage with renewable electricity generation. Technical report, National Renewable Energy Lab. https://www.nrel. gov/docs/fy10osti/47187.pdf

4. Howlader Howlader AM, Urasaki N, Yona A, Senjyu T, Saber AY (2013) A review of output power smoothing methods for wind energy conversion systems. Renew Sustain Energy Rev 26:135-146. https://doi.org/10.1016/j.rser.2013.05.028

5. Santos-Mugica M, Robles E, Endegnanew AG, Tedeschi E, Giebhardt J (2014) Grid integration and power quality testing of marine energy converters: Research activities in the marinet project. In: 9th International conference on ecological vehicles and renewable energies (EVER), Monte-Carlo, Monaco, Mar. 2014. https://doi.org/10.1109/EVER.2014.6844044

6. Uihlein A, Magagna D (2016) Wave and tidal current energya review of the current state of research beyond technology.
Renew Sustain Energy Rev 58:1070-1081. https://doi. org/10.1016/j.rser.2015.12.284

7. Weisser D, Garcia RS (2005) Instantaneous wind energy penetration in isolated electricity grids: concepts and review. Renew Energy 30(8):1299-1308. https://doi.org/10.1016/j. renene.2004.10.002

8. Dabiri JO (2011) Potential order-of-magnitude enhancement of wind farm power density via counter-rotating vertical-axis wind turbine arrays. Renew Sustain Energy Rev. https://doi. org/10.1063/1.3608170

9. Salter S (2012) Are nearly all tidal stream turbine designs wrong for the pentland firth? In: 4th International conference on ocean energy, Dublin, IR, Oct. 2012. http://www.homep ages.ed.ac.uk/shs/Tidal\%20Stream/Vertical\%20axis\%20201 4.pdf

10. Polagye B, Strom B, Ross H, Forbush D, Cavagnaro RJ (2019) Comparison of cross-flow turbine performance under torqueregulated and speed-regulated control. J Renew Sustain Energy 11(4):044501. https://doi.org/10.1063/1.5087476

11. Khan MJ, Bhuyan G, Iqbal MT, Quaicoe JE (2009) Hydrokinetic energy conversion systems and assessment of horizontal and vertical axis turbines for river and tidal applications: A technology status review. Appl Energy 86(19):1823-1835. https:// doi.org/10.1016/j.apenergy.2009.02.017

12. Strom B, Brunton SL, Polagye B (2016) Intracycle angular velocity control of cross-flow turbines. Nat Energy. https:// doi.org/10.1038/nenergy.2017.103

13. Cavagnaro RJ, Strom B, Polagye B, Stewart A (2017) Power collection from multiple hydrokinetic generators utilizing advanced control. In: 12th European wave and tidal energy conference, Cork, IR, Aug. 2017. https://www.semanticscholar .org/paper/Power-Collection-from-Multiple-HydrokineticControl-Cavagnaro-Strom/7a4b695e5dcdde3947625581c b39d2c5b2247beb

14. Ushiwata K, Shishido S, Takahashi R, Murata T, Tamura J (2007) Smoothing control of wind generator output fluctuation by using electric double layer capacitor. In: International conference on electrical machines and systems, Seoul, Korea, Oct. 2007. https://ieeexplore.ieee.org/document/4412246

15. Abedini A, Nasiri A (2008) Applications of super capacitors for pmsg wind turbine power smoothing. In: 34th Annual conference of IEEE industrial electronics, Orlando, Florida, Nov. 2008. https://doi.org/10.1109/IECON.2008.4758497

16. Pegueroles-Queralt J, Bianchi J, Gomis-Bellmunt O (2014) A power smoothing system based on supercapacitors for renewable distributed generation. IEEE Trans Ind Electr 62(1):343350. https://doi.org/10.1109/TIE.2014.2327554

17. Rajapakse G, Jayasinghe SG, Fleming A, Negnevitsky M (2018) Grid integration and power smoothing of an oscillating water column wave energy converter. Energies. https://doi. org/10.3390/en11071871

18. Harb S, Mirjafari M, Balog RS (2013) Ripple-port moduleintegrated inverter for grid-connected pv applications. IEEE Trans Ind Appl 49(6):2692-2698. https://doi.org/10.1109/ TIA.2013.2263783

19. Krein PT, Balog RS, Mirjafari M (2012) Minimum energy and capacitance requirements for single-phase inverters and rectifiers using a ripple port. IEEE Trans Power Electr 27(11):46904698. https://doi.org/10.1109/TPEL.2012.2186640

20. Tan GH, Wang JZ, Ji YC (2007) Soft-switching flyback inverter with enhanced power decoupling for photovoltaic applications. IET Electr Power Appl 1(2):264-274. https://doi. org/10.1049/iet-epa:20060236

21. Aaronson HL (2019) Design and implementation of a power smoothing system for cross-flow current turbines. Master's thesis. http://hdl.handle.net/1773/44377 
22. Zhou Z, Benbouzid M, Charpentier JFédéric, Scuiller Franck, Tang Tianhao (2012) Energy storage technologies for smoothing power fluctuations in marine current turbines. In: IEEE International symposium on industrial electronics, Hangzhou, China, Nov. 2012. https://doi.org/10.1109/ISIE.2012.6237300

23. Staiger J, Bosch S, Steinhart H (2017) Application of a buckboost converter for highly dynamic power smoothing in industrial applications. In: Power conversion and intelligent motion conference, Nuremberg, DE, May 2017. https://ieeex plore.ieee.org/document/7990822

24. Erickson RW, Maksimovic D (2004) Fundamentals of Power Electronics, 2nd edn. Kluwer Academic, Norwell, MA, pp 331-376

25. Brunton SL, Kutz JN (2019) Data-driven science and engineering: machine learning, dynamical systems, and control. Cambridge University Press, Cambridge
26. Jin L, Chan S (1989) A unified and efficient approach for determining Thevenin (Norton) equivalent circuits. IEEE Trans Educ 32(3):408-410. https://doi.org/10.1109/13.34184

27. Press WH, Teukolsky SA, Vetterling WT, Flannery BP (1992) Numerical Recipes in C, 2nd edn. Cambridge University Press, Cambridge

Publisher's Note Springer Nature remains neutral with regard to jurisdictional claims in published maps and institutional affiliations. 